\title{
Precipitação artificial após aplicação do inseticida clorantraniliprole associado com adjuvante em plantas de soja
}

\author{
Artificial precipitation after spray of clorantraniliprole \\ insecticide associated with adjuvant application in soybean plants
}

\begin{abstract}
Adriano Arrué ${ }^{I^{*}}$ Jerson Vanderlei Carús Guedes ${ }^{\mathrm{I}}$ Lindolfo Storck $^{\mathrm{II}}$ Alexandre Swarowsky ${ }^{\mathrm{III}}$ Deise Cagliari ${ }^{\mathrm{I}}$ Leonardo Moreira Burtet ${ }^{\mathrm{I}}$ Jonas André Arnemann ${ }^{\mathrm{I}}$
\end{abstract}

RESUMO

O controle de insetos-praga com inseticidas é um recurso importante para manutenção das altas produtividades na cultura da soja. Porém, pouco se conhece sobre o desempenho de novos inseticidas, tais como, clorantraniliprole em condições adversas, como é o caso das precipitações pluviométricas após a pulverização agrícola. A ação dos adjuvantes associados aos inseticidas é outro fator relacionado à melhora da sua eficiencia. O objetivo deste estudo foi avaliar a influência de quatro períodos de precipitação artificial após a pulverização do inseticida clorantraniliprole $\left(2 \mathrm{~g}\right.$ de ingrediente ativo $\left.\mathrm{h}^{-1}\right)$, misturado com diferentes adjuvantes, visando ao o controle de lagartas na cultura da soja. O experimento foi executado com o uso de duas cultivares (blocos) e seis vasos (2 plantas/vaso) por tratamento fatorial (5x5). O fator adjuvante foi constituído por uma testemunha (sem adjuvante) e quatro adjuvantes (Assist ${ }^{\circledR}$ - 0,5\% do volume de calda, Naturo'il ${ }^{\otimes}-0,5 \%$, Nitro $L L^{\otimes}-6,6 \%\left(10 L \mathrm{ha}^{-1}\right)$ e Silwet $L-77^{\oplus}$ - 0,1\%). O fator precipitação artificial (20mm) foi composto por uma testemunha (sem precipitação) e quatro tempos (1, 120, 240 e 360 minutos) após a pulverização de clorantraniliprole com adjuvantes. Os resultados sugerem que a precipitação de 20 mm, um minuto após a aplicação de clorantraniliprole, reduz a mortalidade de Anticarsia gemmatalis, e que as precipitações após 240 minutos da aplicação de clorantraniliprole não interferem na mortalidade de A. gemmatalis em soja. Os adjuvantes Assist ${ }^{\circledR} e$ Naturo'il ${ }^{\circledR}$ associados ao inseticida clorantraniliprole aumentam a mortalidade de A. gemmatalis na cultura da soja.

Palavras-chave: eficiência, Anticarsia gemmatalis, mortalidade.

\section{ABSTRACT}

The insecticide use on insect pest control is an important tool to keep high yields on soybeans. However, little is known about the behavior of the insecticide in adverse conditions, such as spraying followed by precipitation. The use of adjuvants associated with insecticides is another factor that can be related to improvement of its efficiency. This study aimed to evaluate the effects of the influence of four precipitation periods after the pulverization of the insecticide clorantraniliprole $(2 \mathrm{~g}$ of the active ingredient $\left.\mathrm{ha}^{-1}\right)$. A mixed of different adjuvants on the control of caterpillars on soybeans were evaluated. The assay was performed using two cultivars in six pots ( 2 plants/pots) for a factor scheme of 5x5. The factor adjuvants consisted of one untreated (without adjuvants) and four adjuvants (Assist ${ }^{\circledR}$ - 0,5\%, Naturo'il ${ }^{\circledR}$ 0,5\%, Nitro $L L^{\circledR}-L h a^{-1}$ and Silwet $L-77^{\circledR}-0,1 \%$ ). The factor artificial precipitation (20mm) consisted of one untreated (without precipitation) and four precipitation intervals (1, 120, 240 and 360 minutes) after the application of clorantraniliprole with adjuvants. The results showed that the precipitation of 20mm, 1 minute after the clorantraniliprole pulverization, reduces the Anticarsia gemmatalis mortality, and that the precipitation 240 min after the pulverization does not interfere in the mortality of A. gemmatalis on soybeans. The adjuvants Assist ${ }^{\circledR}$ and Naturo'il ${ }^{\circledR}$ associated to the insecticide clorantraniliprole increases the A. gemmatalis mortality on soybeans.

Key words: efficiency, Anticarsia gemmatalis, mortality.

\section{INTRODUÇÃO}

A lagarta-da-soja, Anticarsia gemmatalis Hübner, 1818 (Lepidoptera: Noctuidae), é uma das principais espécies que causam danos à cultura da soja. As lagartas alimentam-se tanto do limbo foliar como das nervuras foliares (LOURENÇÃO et al., 2010). A sua ocorrência, mesmo em baixas populações, pode provocar grandes danos à cultura da soja, causando desde desfolhamento até a destruição

'Departamento de Defesa Fitossanitária, Universidade Federal de Santa Maria (UFSM), Av. Roraima, nº 1000, Cidade Universitária, 97105-900, Santa Maria, RS, Brasil. E-mail: adrianoarrue @ hotmail.com. *Autor para correspondência.

IUniversidade Tecnológica Federal do Paraná (UTFPR), Pato Branco, PR, Brasil.

${ }^{\mathrm{III} C e n t r o ~ U n i v e r s i t a ́ r i o ~ F r a n c i s c a n o ~(U N I F R A), ~ S a n t a ~ M a r i a, ~ R S, ~ B r a s i l . ~}$ 
completa da planta (SILVA et al., 2002). Entre os principais métodos indicados para o controle dessas lagartas, está a utilização de inseticidas químicos. Os inseticidas piretroides, organofosforados, reguladores de crescimento e, nos últimos anos, as diamidas antranílicas são registrados para o controle de $\boldsymbol{A}$. gemmatalis na cultura da soja (MAPA, 2011).

Os inseticidas do grupo das diamidas antranílicas, ao qual pertence o ingrediente ativo clorantraniliprole, têm como principais características a alta atividade inseticida e a baixa toxicidade aos mamíferos (LAHM et al., 2007). Esses inseticidas se ligam aos receptores de rianodina dos insetos nas células musculares, promovendo a saída descontrolada de cálcio, acarretada pela abertura do canal, provocando a paralisia muscular e a morte do inseto (CORDOVA et al., 2006).

Alguns fatores podem afetar a eficácia dos inseticidas, entre eles, a ocorrência de precipitações pluviométricas. A ação da água pode remover parte do produto da folha, reduzindo sua absorção e o período de proteção (DINARDO-MIRANDA et al., 2004). $\mathrm{O}$ inseticida flonicamida tem sua eficácia reduzida quando ocorrem precipitações primeiras quatro horas após a pulverização (FORTUNATO et al., 2011). Entretanto, os inseticidas têm comportamentos diferentes em relação à influência das precipitações pluviométricas, devido, principalmente, a características intrínsecas dos produtos e a sua formulação (MASHAYA, 1993).

Uma estratégia que pode amenizar o efeito das precipitações pluviométricas é a utilização de adjuvantes em determinadas aplicações de defensivos agrícolas (TAYLOR \& MATTHEWS, 1986). Na cultura do arroz, o uso de adjuvantes melhora a deposição do inseticida triazofós e a sua persistência na planta em condições de precipitação pluviométrica (SHI et al., 2009).

Com base no exposto, o objetivo deste estudo foi avaliar a influência de diferentes períodos de precipitação artificial após a pulverização e a associação de diferentes adjuvantes com o inseticida clorantraniliprole, na mortalidade de A. gemmatalis.

\section{MATERIAL E MÉTODOS}

O experimento foi conduzido em vasos (capacidade de 11 litros e $26 \mathrm{~cm}$ de diâmetro superior), expostos em bancadas dentro de uma estufa plástica localizada no município de Santa Maria, Rio Grande do Sul. Nos vasos, foi colocado solo retirado da camada superficial $(0$ a $10 \mathrm{~cm})$ de uma área de cultivo agrícola anual. Neste solo, foi misturado
$400 \mathrm{~kg} \mathrm{ha}^{-1}$ da fórmula N-P-K 0-18-28. As sementes de soja foram tratadas e homogeneizadas em tambor rotativo de eixo excêntrico, com fipronil $(50 \mathrm{~mL}$ para $100 \mathrm{~kg}$ de sementes), Carbendazim $(30 \mathrm{~mL}$ para $100 \mathrm{~kg}$ de sementes), thiram $(70 \mathrm{~mL}$ para $100 \mathrm{~kg}$ de sementes) e estirpes de Bradyrhizobium japonicum (300mL para $50 \mathrm{~kg}$ de sementes). A semeadura nos vasos foi realizada em 3 de fevereiro de 2011, sendo 10 sementes por vaso e, 15 dias após a emergência, procedeu-se o desbaste, deixando duas plantas por vaso até o final do experimento.

O experimento foi realizado em esquema fatorial no delineamento blocos ao acaso. Foram utilizadas duas cultivares de soja (BMX Potência RR e Fundacep 53 RR), com objetivo de produzir resultados de maior abrangência. Para análise de dados, os resultados de cada cultivar foram utilizados como repetição (bloco $=$ cultivar), sendo que cada repetição era composta por 24 potes com lagartas. As unidades experimentais (EU) foram constituídas de seis vasos de cada cultivar, sendo que, de cada unidade experimental, foram coletados quatro folíolos. Nas $\mathrm{UE}$, foram aplicados os tratamentos fatoriais $(5 \times 5)$, sendo esses constituídos por diferentes adjuvantes e tempos para a precipitação.

$\mathrm{O}$ fator adjuvante ao inseticida foi composto por: sem adjuvante (testemunha), Assist ${ }^{\circledR}$ (Óleo mineral) - 0,5\% do volume de calda, Naturo'il ${ }^{\circledR}$ (Óleo vegetal) - 0,5\% do volume de calda, Nitro $\mathrm{LL}^{\circledR}$ (Óleo nitrogenado) - 6,6\% do volume de calda $\left(10 \mathrm{~L} \mathrm{ha}{ }^{-1}\right)$ e Silwet L-77 ${ }^{\circledR}$ (Organo-siliconado) $0,1 \%$ do volume de calda. $\mathrm{O}$ inseticida utilizado foi clorantraniliprole, na formulação comercial Premio $\mathrm{SC}^{\circledR}$ na dose de $10 \mathrm{~mL}$ doproduto comercial ha ${ }^{-1}$ ou $2 \mathrm{~g}$ de ingrediente ativo ha ${ }^{-1}$.

Para a aplicação do inseticida com adjuvante, em 22/04/2011 (temperatura de $25,3^{\circ} \mathrm{C}$, umidade relativa do ar $65 \%$ e velocidade do vento de $1 \mathrm{~km} \mathrm{~h}^{-1}$ ), foi utilizado um pulverizador costal, pressurizado com $\mathrm{CO}_{2}$, calibrado para volume de calda de $150 \mathrm{~L} \mathrm{ha}^{-1}$, equipado com barra de $2 \mathrm{~m}$, quatro bicos espaçados em $0,5 \mathrm{~m}$, e pontas de pulverização jato plano Teejet XR 110.02 com pressão de 30 psi. Nesta data, a soja se encontrava no estádio fenológico $\mathrm{R} 4 \mathrm{e}$ com aproximadamente $80 \mathrm{~cm}$ de altura.

O fator tempo para precipitação artificial (20mm) foi composto por: sem precipitação (testemunha), 1, 120, 240 e 360 minutos após a pulverização do inseticida com adjuvante. A precipitação artificial foi realizada com um simulador 
de precipitação estacionário de bicos múltiplos e oscilantes, desenvolvido pelo National Soil Erosion Research Lab, USDA - ARS, USA (NORTON \& BROWN, 1992). O simulador de precipitação foi instalado a $2,45 \mathrm{~m}$ acima da superfície do solo e regulado para intensidade de $120 \mathrm{~mm} \mathrm{~h}^{-1}$ durante 10 minutos, totalizando $20 \mathrm{~mm}$ de precipitação. O esquema da precipitação e avaliação dos tratamentos está descrito na figura 1.

Duas horas após a realização da precipitação artificial, foram coletados os folíolos dos vasos tratados. Esses foram cortados em sessões de $15 \mathrm{~cm}^{2}$ e cada uma das sessões foram colocadas individualmente em potes com papel filtro umedecido, com o objetivo de manter a turgescência da folha durante o período de avaliação. Em cada pote foi colocada uma lagarta Anticarsia gemmatalis de $2^{\circ}$ ou $3^{\circ}$ ínstar, provenientes de criação massal em laboratório, mantidas sob condições controladas (UR: $75 \% \pm 12$ e T: $25^{\circ} \mathrm{C} \pm 2$ ). As avaliações do número de lagartas mortas foram realizadas após 48 , 72, 96 e 120 horas após a sua colocação em contato com as folhas, para determinação da eficiência biológica dos tratamentos. Os valores da proporção de lagartas mortas foram transformados em arcoseno. As médias foram comparadas pelo teste de Duncan (valor-p=0,05). Foi usado o aplicativo computacional NTIA/EMBRAPA.

\section{RESULTADOS E DISCUSSÃO}

Pela análise de variância, não foi constatada interação significativa entre adjuvantes e tempo para precipitação, sendo os efeitos principais significativos pelo teste $\mathrm{F}$ (valor-p $<0,05)$. Assim, a ação do tempo sobre a proteção do inseticida é a mesma para os diferentes adjuvantes.

O número de lagartas mortas, após 48 horas de contato com os folíolos tratados, foi diferente em relação ao tempo para a precipitação (Tabela 1). Não houve diferença na mortalidade de lagartas, entre o tratamento sem precipitação e o tratamento com uma precipitação de $20 \mathrm{~mm}$, realizada aos 360 min após a aplicação do inseticida. Esses resultados comprovam que a ocorrência de precipitações seis horas após a pulverização não apresentam efeito negativo na eficiência do inseticida clorantraniliprole, independente do adjuvante. Os tratamentos em que as precipitações foram realizadas 120 e 240 minutos após a pulverização resultaram em mortalidade de Anticarsia gemmatalis próxima a 50\%, não diferindo entre si. A menor mortalidade de lagartas ocorreu no tratamento com precipitação 1 min após a pulverização, que resultou em apenas $30 \%$ de mortalidade.

$\mathrm{O}$ efeito negativo das precipitações realizadas aos $120 \mathrm{~min}, 240 \mathrm{~min}$, e principalmente $1 \mathrm{~min}$ após a pulverização, está relacionado,

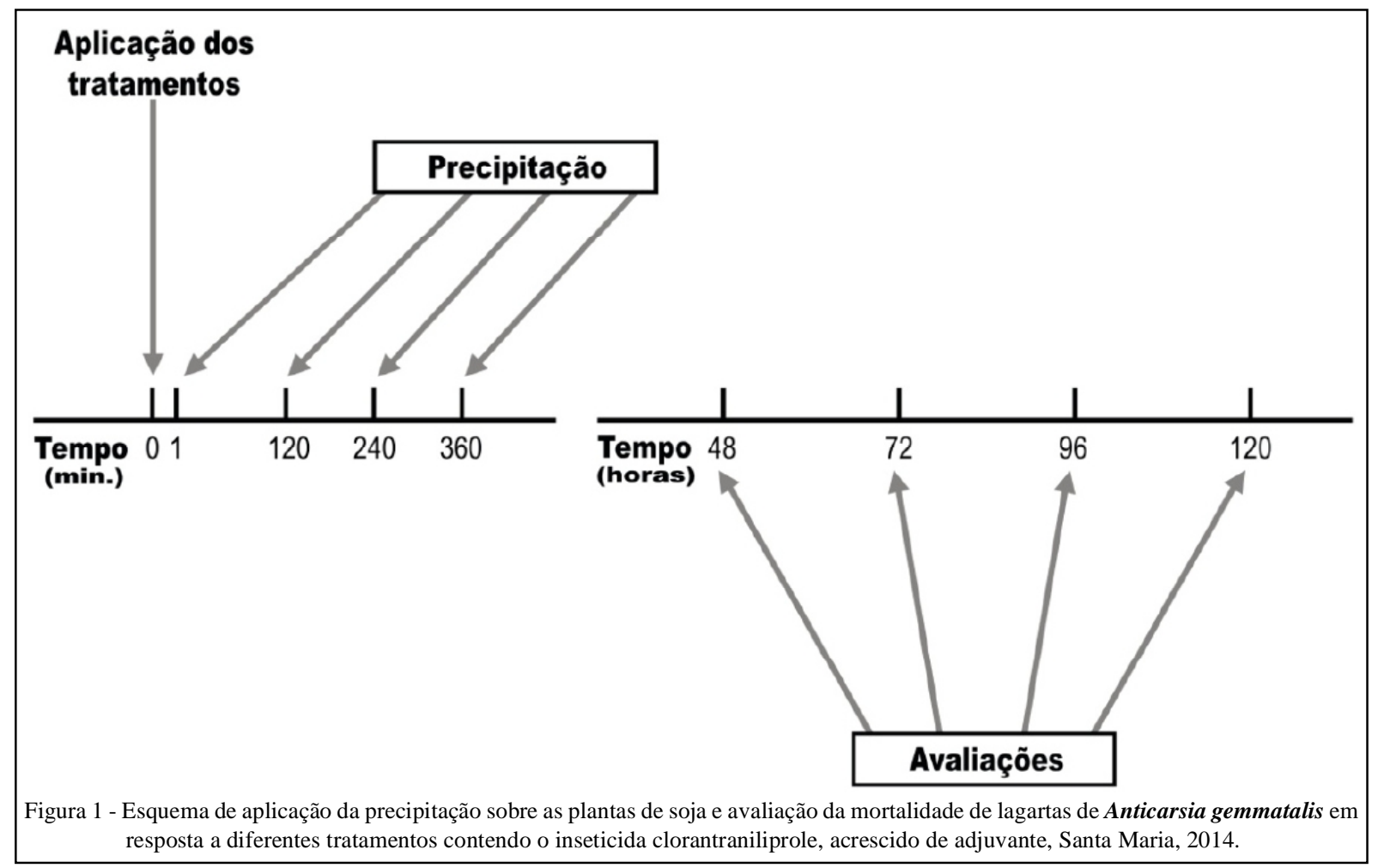

Ciência Rural, v.44, n.12, dez, 2014. 
Tabela 1 - Efeito do tempo de aplicação de precipitação artificial, em plantas de soja tratadas com o inseticida clorantraniliprole, sobre a mortalidade de lagartas de Anticarsia gemmatalis. Santa Maria, 2014.

\begin{tabular}{|c|c|c|c|c|c|c|c|c|}
\hline \multirow{2}{*}{$\begin{array}{l}\text { Tempo } \\
\text { (minutos) }\end{array}$} & \multicolumn{2}{|c|}{ 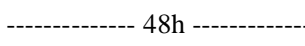 } & \multicolumn{2}{|c|}{ - $72 \mathrm{~h}$--- } & \multicolumn{2}{|c|}{ - $96 h$------ } & \multirow[b]{2}{*}{$\mathrm{N}$} & \multirow[b]{2}{*}{$\mathrm{N} \%$} \\
\hline & $\mathrm{N}^{1}$ & $\mathrm{~N} \%^{2}$ & $\mathrm{~N}$ & $\mathrm{~N} \%$ & $\mathrm{~N}$ & $\mathrm{~N} \%$ & & \\
\hline Sem precipitação & $38 a^{*}$ & 80 & $44 \mathrm{a}$ & 92 & $46 \mathrm{a}$ & 95 & $46 \mathrm{a}$ & 95 \\
\hline 1 & $14 \mathrm{c}$ & 30 & $27 \mathrm{c}$ & 56 & $33 \mathrm{c}$ & 69 & $34 \mathrm{~b}$ & 70 \\
\hline 120 & $25 \mathrm{~b}$ & 52 & $38 \mathrm{~b}$ & 80 & $42 \mathrm{~b}$ & 88 & $42 \mathrm{~b}$ & 88 \\
\hline 240 & $24 \mathrm{~b}$ & 51 & $41 \mathrm{~b}$ & 85 & $43 \mathrm{ab}$ & 89 & $43 \mathrm{ab}$ & 89 \\
\hline 360 & $32 \mathrm{a}$ & 67 & $40 \mathrm{~b}$ & 84 & $43 \mathrm{ab}$ & 89 & $43 \mathrm{ab}$ & 89 \\
\hline Média & 26,6 & - & 38,0 & - & 41,2 & - & 41,8 & - \\
\hline $\mathrm{CV}(\%)^{3}$ & \multicolumn{2}{|c|}{18,3} & \multicolumn{2}{|c|}{12,3} & \multicolumn{2}{|c|}{13,1} & \multicolumn{2}{|c|}{22,8} \\
\hline
\end{tabular}

*Médias não ligadas pela mesma letra, na coluna, diferem pelo teste de Duncan (5\%).

${ }^{1} \mathrm{~N}$ (número de lagartas mortas); ${ }^{2} \mathrm{~N} \%$ (percentagem de lagartas mortas); ${ }^{3} \mathrm{CV}$ (Coeficiente de variação).

provavelmente, à baixa quantidade de ingrediente ativo restante na superfície foliar. Esse fato se deve à ação da água, que provoca lixiviação do inseticida e consequentemente uma redução da eficiência de controle da praga (COHEN \& STEINMETZ, 1986).

$\mathrm{Na}$ avaliação das 72 horas, do contato da lagarta com os folíolos tratados, o tratamento sem precipitação apresentou uma mortalidade de $92 \%$, demonstrando que o inseticida clorantraniliprole foi eficiente no controle de $\boldsymbol{A}$. gemmatalis (Tabela 1 ). As precipitações aos 120, 240 e 360min apresentaram um controle eficiente, ou seja, superior a $80 \%$. O tratamento com precipitação de $1 \mathrm{~min}$ após a pulverização obteve as menores mortalidades (56\%), também na avaliação das 72 horas, diferindo dos demais tratamentos.

Nasavaliações das 96e 120horas, docontato da lagarta com os folíolos tratados, os resultados foram similares. Assim, percebe-se uma estabilização do controle pelo inseticida (Tabela 1). Não houve diferença entre os tratamentos sem precipitação e com precipitações de $20 \mathrm{~mm}$, realizadas $240 \mathrm{~min}$ e $360 \mathrm{~min}$ após a pulverização. Como nas demais avaliações as precipitações realizadas $1 \mathrm{~min}$ e $120 \mathrm{~min}$ após a aplicação do inseticida clorantraniliprole interferiram negativamente na mortalidade de lagartas, indicando lixiviação e consequentemente uma menor absorção do inseticida até $120 \mathrm{~min}$ depois da pulverização.

Analisando os resultados das últimas avaliações (96 e 120 horas), verifica-se que, quando o intervalo foi de $240 \mathrm{~min}$ entre a pulverização e a precipitação, provavelmente, houve tempo de o inseticida ser absorvido pelas folhas e atuar sobre A. gemmatalis, quando essa foi retirada. Assim, a precipitação de $20 \mathrm{~mm}$, realizada $240 \mathrm{~min}$ após a pulverização, tem influência no efeito de choque, porém, no controle final, não apresenta diferença para o inseticida clorantraniliprole. Isso se explica pela quantidade de ingrediente ativo, que, embora não tenha sido suficiente para demonstrar controle superior nas primeiras avaliações, nas últimas avaliações (96 e 120 horas), não diferiu significativamente dos melhores tratamentos. Em relação à precipitação realizada $1 \mathrm{~min}$ após a pulverização, a mortalidade foi de $70 \%$, demonstrando que parte do ingrediente ativo aplicado foi rapidamente absorvida pelos tecidos dos folíolos, logo após o contato com eles.

Com base nos resultados, verifica-se que a aplicação de uma precipitação artificial de $20 \mathrm{~mm}$, 1 min após a pulverização, apresentou a maior interferência sobre a mortalidade de lagartas, seguida de 120min. As precipitações realizadas 240 e 360 min, praticamente se equivalem com o tratamento sem precipitação. Isso ratifica que existe relação direta com o tempo decorrido entre a aplicação e a precipitação e a diminuição da eficácia do inseticida (WILLIS et al., 1992). As precipitações que ocorreram 240 min após a pulverização do inseticida clorantraniliprole não interferiram na mortalidade de lagartas de $\boldsymbol{A}$. gemmatalis na cultura da soja, com exceção da avaliação de 48 horas. Esse fato que está relacionado com a diminuição do efeito de choque do produto, pela menor quantidade de ingrediente ativo.

O conhecimento da influência das precipitações sobre a eficácia dos inseticidas é de suma importância (HULBERT et al., 2011). Entretanto, os resultados do efeito da precipitação sobre a eficiência do inseticida clorantraniliprole não podem 
ser extrapolados para outros inseticidas, devido aos produtos responderem de maneira diferente, de acordo com suas características intrínsecas.

Os resultados da associação dos adjuvantes com o inseticida mostraram, na avaliação de 48 horas após a colocação das lagartas em contado com os folíolos tratados, que a utilização de Assist ${ }^{\circledR}$ resultou num incremento na mortalidade de $\boldsymbol{A}$. gemmatalis (Tabela 2). O aumento da mortalidade das lagartas pela adição do adjuvante Assist ${ }^{\circledR}$ está relacionado à maior penetração do produto na camada cerosa da superfície foliar (AZEVEDO, 2011). O tratamento com adição de Naturo'il ${ }^{\circledR}$ obteve resultado semelhante à aplicação isolada do inseticida clorantraniliprole. Entretanto os adjuvantes, Nitro LL ${ }^{\circledR}$ e Silwet L-77 ${ }^{\circledR}$, resultaram numa redução da mortalidade de lagartas.

$\mathrm{Na}$ avaliação de 72 horas, os dados evidenciam que a associação do inseticida aos adjuvantes Assist ${ }^{\circledR}$ e Naturo'il $^{\circledR}$ resultou nos melhores resultados, com mortalidade de A. gemmatalis acima de $80 \%$ (Tabela 2). O uso destes adjuvantes pode resultar em uma melhora na eficácia de clorantraniliprole. Segundo ARAÚJO \& RAETANO (2011), tanto óleos minerais como vegetais podem melhorar a eficiência biológica, quando aplicados em associação com inseticidas e fungicidas. A adição dos adjuvantes, Nitro LL ${ }^{\circledR}$ e Silwet L-77 ${ }^{\circledR}$, não diferiu da aplicação isolada do inseticida.

Nas avaliações de 96 e 120 horas após o contato das lagartas com folíolos tratados, os resultados encontrados foram similares, indicando uma estabilização da mortalidade (Tabela 2). Os melhores resultados foram obtidos com a adição de Assist ${ }^{\circledR}$ e Naturo'il ${ }^{\circledR}$, confirmando que estes adjuvantes podem melhorar o controle de lagartas de $\boldsymbol{A}$. gemmatalis em soja. Os demais adjuvantes associados à clorantraniliprole não diferiram da aplicação isolada do inseticida.
Os resultados obtidos pela utilização de Assist ${ }^{\circledR}$ associado ao inseticida estão relacionados com características dos óleos minerais. De acordo com CURRAN et al. (1999), os óleos minerais promovem um aumento da cobertura da folha, além de diminuir a volatilidade e a fotodegradação dos produtos. Dessa forma, melhoram a eficácia do inseticida, por meio da cobertura mais uniforme e da proteção do ingrediente ativo.

A utilização de determinados adjuvantes pode melhorar efetivamente a eficiência biológica dos inseticidas. Entretanto, essa melhora não é válida para todos os adjuvantes, pois deve ser levado em conta o produto utilizado e o alvo biológico. Os adjuvantes, a base de óleos minerais e vegetais, podem ser uma opção viável para melhorar o desempenho do inseticida clorantraniliprole no controle de $\boldsymbol{A}$. gemmatalis em soja.

\section{CONCLUSÃO}

As precipitações, um minuto após a aplicação de clorantraniliprole, diminuem a mortalidade de Anticarsia gemmatalis em soja. Precipitações após 240 minutos da aplicação do inseticida clorantraniliprole, não afetam a eficiência desse inseticida. A adição dos adjuvantes Assist ${ }^{\circledR}$ e Naturo' 'il ${ }^{\circledR}$ ao inseticida clorantraniliprole auxiliam no aumento da mortalidade de A. gemmatalis, indicando, assim, uma melhor proteção de clorantraniliprole à lavagem pelas precipitações pluviométricas.

\section{AGRADECIMENTOS}

Os autores agradecem aos colaboradores do Laboratório de Manejo Integrado de Pragas (LabMIP) da Universidade Federal de Santa Maria (UFSM) e a Coordenação de Aperfeiçoamento de Pessoal de Nível Superior (CAPES) pelo financiamento da pesquisa.

Tabela 2 - Efeito da utilização de adjuvantes, em plantas de soja tratadas com o inseticida clorantraniliprole, sobre a mortalidade de lagartas de Anticarsia gemmatalis. Santa Maria, 2014.

\begin{tabular}{|c|c|c|c|c|c|c|c|c|}
\hline Adjuvantes & $\mathrm{N}^{1}$ & $\mathrm{~N} \%^{2}$ & $\mathrm{~N}$ & $\mathrm{~N} \%$ & $\mathrm{~N}$ & $\mathrm{~N} \%$ & $\mathrm{~N}$ & $\mathrm{~N} \%$ \\
\hline Sem adjuvante & $28 b^{*}$ & 59 & $37 \mathrm{~b}$ & 77 & $41 \mathrm{bc}$ & 85 & $43 a b$ & 90 \\
\hline Assist & $34 \mathrm{a}$ & 72 & $44 \mathrm{a}$ & 91 & $44 \mathrm{a}$ & 92 & $44 \mathrm{a}$ & 92 \\
\hline Naturo'il & $28 \mathrm{~b}$ & 59 & $42 \mathrm{a}$ & 87 & $44 \mathrm{a}$ & 92 & $44 \mathrm{a}$ & 92 \\
\hline Nitro LL & $21 \mathrm{c}$ & 43 & $34 \mathrm{~b}$ & 72 & $38 \mathrm{c}$ & 80 & $39 \mathrm{~b}$ & 82 \\
\hline Silwet L-77 & $23 \mathrm{bc}$ & 48 & $34 \mathrm{~b}$ & 72 & $37 \mathrm{c}$ & 77 & $40 \mathrm{~b}$ & 84 \\
\hline Média & 26,8 & - & 38,2 & - & 40,8 & - & 42,0 & - \\
\hline $\mathrm{CV}(\%)^{3}$ & \multicolumn{2}{|c|}{18,3} & \multicolumn{2}{|c|}{12,3} & \multicolumn{2}{|c|}{13,1} & \multicolumn{2}{|c|}{22,8} \\
\hline
\end{tabular}

*Médias não ligadas pela mesma letra, na coluna, diferem pelo teste de Duncan (5\%).

${ }^{1} \mathrm{~N}$ (número de lagartas mortas); ${ }^{2} \mathrm{~N} \%$ (percentagem de lagartas mortas); ${ }^{3} \mathrm{CV}$ (Coeficiente de variação).

Ciência Rural, v.44, n.12, dez, 2014. 


\section{REFERÊNCIAS}

ARAÚJO, D.; RAETANO, C.G. Adjuvantes de produtos fitossanitários. In: ANTUNIASSI, U. R.; BOLLER, W. Tecnologia de aplicação para grandes culturas. Passo fundo: Aldeia Norte, 2011. p.27-49.

AZEVEDO, L.A.S. Adjuvantes agrícolas para a proteção de plantas. Seropédica: IMOS, 2011. 264p.

COHEN, M.L.; STEINMETZ, W.D. Foliar Washoff of pesticides by Rainfall. Environmet Science Technology, v.20, p.521-523, 1986.

CORDOVA, D. et al. Anthranilicdiamides: a new class of insecticides with a novel mode of action, ryanodine receptor activation. Pesticide Biochemistry and Physiology, v.84, p.196-214, 2006. Disponível em: <http://dx.doi.org/10.1016/j. pestbp.2005.07.005>. Acesso em: 13 jan. 2012. doi:10.1016/j. pestbp.2005.07.005.

CURRAN, W.S. et al. Adjuvants for enhancing herbicide performance. In: AGRONOMY FACTS 37. Pennsylvania: Penn State College of Agricultural Sciences, 1999. p.1-5.

DINARDO-MIRANDA, L.L. et al. Influência da época de aplicação de inseticidas no controle de Mahanarvafimbriolata (Stål) (Hemiptera: Cercopidae), na qualidade e na produtividade da cana-de-açúcar. Neotropical Entomology, v.33, p.091098, 2004.Disponivel em: <http://dx.doi.org/10.1590/S1519566X2002000400014>. Acesso em: 07 jan. 2012.doi: 10.1590/ S1519-566X2002000400014.

FORTUNATO, R.P. et al. Simulate rain about action insecticide flonicamid in the control of the cotton aphid. Acta Scientiarum Agronomy, v.33, p.603-606, 2011. Disponível em: <http://dx.doi org/10.4025/actasciagron.v33i4.11160>. Acesso em: 13 jan. 2012. doi: 10.4025/actasciagron.v33i4.11160.

HULBERT, D. et al. Rainfastness and residual activity of insecticides to control Japanese Beetle (Coleoptera: Scarabaeidae) in grapes. Journal of Economic Entomology, v.104, p.16561664, 2011. Disponível em: 〈http://dx.doi.org/10.1603/EC11077〉. Acesso em: 06 jan. 2012. doi: 10.1603/EC11077.
LAHM, G.P. et al. Rynaxypyr ${ }^{\mathrm{TM}}$ : A new insecticidal anthranilicdiamide that acts as a potent and selective ryanodine receptor activator. Bioorganic \& Medicinal Chemistry Letters, v.17, p.6274-6279, 2007. Disponível em: <http://dx.doi. org/10.1016/j.bmcl.2007.09.012>. Acesso em: 13 jan. 2012. doi: 10.1016/j.bmcl.2007.09.012.

LOURENÇÃO, A.L. et al. Produtividade de genótipos de soja sob infestação da lagarta-da-soja e de percevejos. Neotropical Entomology, v.39, p.275-281, 2010. Disponível em: <http:// dx.doi.org/10.1590/S1519-566X2010000200020>. Acesso em: 06 jan. 2012. doi: 10.1590/S1519-566X2010000200020.

MAPA (MINISTÉRIO DA AGRICULTURA PECUÁRIA E ABASTECIMENTO). Disponível em: <http://http://extranet. agricultura.gov.br/agrofit_cons/principal_agrofit_cons/>. Acesso em: 10 nov. 2011.

MASHAYA, N. Effect of simulated rain on efficacy if insecticide deposits on tobacco. Crop Protection, v.12, p.5558, 1993. Disponível em: <http://dx.doi.org/10.1016/02612194(93)90020-J>. Acesso em: 16 jan. 2012.doi:10.1016/02612194(93)90020-J.

NORTON, L.D.; BROWN, L.C. Time-effect on water erosion for ridge tillage. Transactions of the ASAE, v.35, p.473-478, 1992.

SHI, L. et al. The influence of triazophos deposition on rice leaves by adding spray adjuvants. Scientia Agricultura Sinica, v.12, p.4228-4233, 2009

SILVA, F.B. et al. Função fisiológica de lipoxigenases de folhas de soja submetidas ao ataque de lagarta (Anticarsiagemmatalis HÜBNER.). Arquivo do Instituto Biológico, v.69, p.67-74, 2002.

TAYLOR, N.; MATTHEWS, G.A. Effect of different adjuvants on the rainfastness of bendiocarb applied to Brussels sprout plants. Crop protection v.5 p.250-253, 1986.

WILLIS, G.H. et al. Foliar Washoff of Oil-Applied Malathion and Permethrin as a Function of Time after Application. Journal of Agricultural and Food Chemistry, v.40, p.1086-1089, 1992. 